\title{
LA RECLAMACIÓN POR DAÑOS URBANÍSTICOS ENTRE ADMINISTRACIONES PÚBLICAS
}

\author{
JOSÉ FRANCISCO FERNÁNDEZ GARCÍA \\ Universidad de Oviedo
}

\author{
Cómo citar/Citation \\ Fernández García, J. F. (2021). \\ La reclamación por daños urbanísticos entre Administraciones públicas. \\ Revista de Administración Pública, 216, 293-321. \\ doi: https://doi.org/10.18042/cepc/rap.216.10
}

\section{Resumen}

La anulación de un plan general de urbanismo puede obedecer a causas diversas, entre ellas la acción descuidada de una Administración u organismo público distintos de aquella que ha impulsado la aprobación de ese instrumento. Partiendo del estudio de la doctrina judicial aplicable, se analizan en este artículo los mecanismos para obtener el resarcimiento de los daños producidos por ese motivo y, de manera especial, la posibilidad de que una Administración pública puede ejercitar frente a otra la acción de responsabilidad patrimonial en el ámbito urbanístico. Así mismo, se examina hasta qué punto la teoría de la actio nata puede verse modulada en estos supuestos y cómo han de concurrir los requisitos de fondo para que pueda verse reconocida la pretensión de resarcimiento. A tal efecto, se aborda cómo la falta de motivación de un acuerdo puede derivar en un daño antijurídico; qué posibles títulos de imputación pueden concurrir en estos casos, más allá del propio ejercicio de la potestad urbanística; o cómo el nexo entre la acción y el daño patrimonial sufrido puede mantenerse vivo cuando la anulación de un plan obedece a causas externas y sobrevenidas a este.

\section{Palabras clave}

Responsabilidad patrimonial; urbanismo. 


\begin{abstract}
The annulment of a general urban plan may be due to several causes, including the negligent action of a public administration or body, different from the one that has promoted the approval of that instrument. Based on the review of the applicable judicial doctrine, this article analyses the mechanisms for obtaining compensation for damage caused by this reason and, in particular, the possibility that a public administration may bring an action for patrimonial liability against another public administration in the field of urban planning. It is also examined to what extent the theory of actio nata can be modulated in these cases and how the substantive requirements met in order for the claim for compensation to be recognized. To that end, it addresses how the lack of motivation of an agreement can lead to an anti-juridical damage; what possible titles of imputation can concur in these cases, beyond the exercise of urban planning power itself; or how the link between the action and the patrimonial damage suffered can be kept alive when the annulment of a plan is due to external supervening causes.
\end{abstract}

\title{
Keywords
}

Patrimonial liability; urban planning. 


\section{SUMARIO}

I. PLANTEAMIENTO DE LA CUESTIÓN. II. EL USO DE LA «ACCIÓN DE REGRESO» ENTRE ADMINISTRACIONES POR DAÑOS URBANÍSTICOS CAUSADOS A TERCEROS. III. LA RECLAMACIÓN DE RESPONSABILIDAD PATRIMONIAL COMO MECANISMO PARA RESARCIR LOS DAÑOS QUE UNA ADMINISTRACIÓN CAUSA A OTRA EN EL ÁMBITO URBANÍSTICO: 1. La discusión acerca de la legitimación para el ejercicio de la acción. 2. El plazo de prescripción para formular la correspondiente reclamación por daños: la aplicación a estos supuestos de la teoría de la «actio nata». 3. La concurrencia de los requisitos de fondo para que surja el deber de resarcir los daños: 3.1. El daño o lesión patrimonial. 3.2. La antijuridicidad del daño: la «irracionalidad» en el actuar de la Administración frente a la que se dirige la acción. 3.3. Títulos de imputación del daño. 3.4. La relación de causalidad entre la acción y el daño sufrido: el supuesto de los planes urbanísticos anulados por causas externas y sobrevenidas. IV. LA POSIBILIDAD DE QUE TERCEROS PERJUDICADOS TAMBIEN PUEDAN DIRIGIRSE FRENTE A LA ADMINISTRACIÓN QUE HA SUFRIDO EL DAÑO. V. CONCLUSIONES.

\section{PLANTEAMIENTO DE LA CUESTIÓN}

La anulación de cualquier figura del planeamiento produce efectos de gran calado económico, toda vez que aquellos desarrollos urbanísticos en marcha, que no encuentren sustento en una norma o plan anterior, estarían abocados a correr idéntica suerte ante el eventual riesgo de ser impugnados por un tercero, mediante el ejercicio de la acción pública urbanística.

Por ello es frecuente que la expulsión de un plan del ordenamiento conduzca a que la Administración urbanística deba hacer frente a las reclamaciones de responsabilidad patrimonial que le formulen los promotores o particulares, en orden al resarcimiento de la lesión o perjuicio causado ${ }^{1}$.

1 Véase J. A. Chinchilla Peinado (1998), «Urbanismo y responsabilidad patrimonial», Revista de Derecho Urbanístico y Medio Ambiente, 162, págs. 55-106; R. R. Galán Vioque (2002), «La anulación de un plan urbanístico como fuente de responsabilidad patrimonial de las Administraciones Públicas», Revista Andaluza de Administración Pública, 46, págs. 
Pero, en ciertos casos, las circunstancias que determinan la anulación de un plan urbanístico son ajenas a la acción de la Administración pública que impulsó su aprobación, resultando, en cambio, achacables a la intervención de otras Administraciones u organismos públicos, en ese mismo procedimiento o en otros conexos a él ${ }^{2}$.

Surge así, en primer lugar, la cuestión de si, en tales supuestos, la Administración autora del plan puede repetir frente a otra el coste de las indemnizaciones que deba abonar a los particulares.

A la vez, será preciso examinar si dicha Administración también puede reclamar a ese otro ente público que le resarza los daños que a ella misma se le irroguen, como consecuencia de la anulación del planeamiento.

Así delimitado el objeto de este estudio, nos encontramos ante dos vías posibles para el resarcimiento de los daños urbanísticos entre Administraciones públicas: el ejercicio de la acción de regreso y la reclamación de responsabilidad patrimonial.

\section{EL USO DE LA «ACCIÓN DE REGRESO» ENTRE ADMINISTRACIONES POR DAÑOS URBANÍSTICOS CAUSADOS A TERCEROS}

La primera de las cuestiones planteadas, aunque con algún matiz, ha sido objeto de una respuesta más nítida por parte de la doctrina judicial.

En este sentido, puede afirmarse que las Administraciones públicas que intervienen en la tramitación de los planes, cuando estos son anulados por vicios intrínsecos al mismo, responden solidariamente frente al ciudadano, que podrá dirigir su acción contra cualquiera de ellas o, indistintamente, contra ambas a la vez.

Esta doctrina se recoge en la STS de 11 de diciembre de 2002, que apunta a la posterior sustanciación de ese resarcimiento a través de las relaciones internas

191-226; A. Jiménez-Blanco (2008), «Urbanismo y responsabilidad patrimonial: la jurisprudencia existente y los criterios de la Ley del suelo de 2007", en El Derecho urbanistico del siglo XXI: libro homenaje al profesor Martín Bassols Coma, vol. 1 (Urbanismo y vivienda), págs. 293-322; L. Martín Rebollo (1993), La responsabilidad patrimonial de las administraciones públicas en el ámbito urbanístico, Santander: Universidad de Cantabria.

2 Véase J. F. Fernández García (2016), «La anulación de los planes urbanísticos por causas externas y sobrevenidas», Revista Española de Derecho Administrativo, 181, págs. 417-450; T.-R. Fernández Rodríguez (2017), «El contencioso urbanístico y su necesaria reforma», Revista de Administración Pública, 203, págs. 137-162; J. R. Fernández Torres (2017), «La paradoja de la insuficiencia de recursos hídricos hunde el Plan General de Santander. A propósito de la STS de 8 de noviembre de 2016", Revista de Administración Pública, 203, págs. 165-183. 
entre las Administraciones públicas intervinientes, con el fin de determinar su respectivo ámbito de responsabilidad ${ }^{3}$ :

Sea o no aplicable al caso el artículo 140 de la Ley 30/1992, de 26 de noviembre (que parece que sí lo es, aunque sea por analogía, ya que nos encontramos ante una actuación que, si no es propiamente "colegiada» entre varias Administraciones Públicas, es en todo caso "compartida»), lo cierto es que la solución de la responsabilidad solidaria entre Administración Autonómica y Ayuntamiento en la aprobación de los Planes de Urbanismo es plenamente conforme a una jurisprudencia ya consolidada de este Tribunal Supremo, expresada, entre otras, en sentencias de 15 de noviembre de 1993, 2 de febrero de 1999 y 18 de marzo de 1999. Todo ello, desde luego, sin perjuicio de las relaciones internas entre ambas Administraciones Públicas.

En desarrollo de esa doctrina se pronuncia, a su vez, la STSJ de Madrid de 2 de marzo de 2016, señalando que, en el caso de la tramitación de los planes urbanísticos, las distintas Administraciones intervinientes suelen concurrir en la producción del daño, siendo además el plan una norma de carácter reglamentario, sobre la cual la comunidad autónoma ejerce el oportuno control de legalidad ${ }^{4}$ :

Del pago de la indemnización han de responder solidariamente el Ayuntamiento de Pozuelo de Alarcón y la Comunidad de Madrid, conforme a lo dispuesto en el artículo 140 de la Ley 30/1992, porque aunque las determinaciones sobre los usos del Área de Planeamiento Específico 2.6-02, "Urbanización Villasierra», se enmarcan en el ámbito de la autonomía municipal, se está en el caso de que la Comunidad de Madrid no ejerció adecuadamente el control de legalidad, al aprobar definitivamente la Revisión del Plan General que contenía determinaciones inmotivadas, defecto que dio lugar a la declaración judicial de la nulidad de las mismas.

Idéntica posición mantiene, a su vez, la STSJ del País Vasco de 27 de octubre de $2006^{5}$, que con apoyo de la mencionada doctrina del Tribunal Supremo, señala:

Ya antes de la entrada en vigor de la Ley 4/1999, de 13 de enero, que introdujo ese último párrafo, la jurisprudencia se había pronunciado en idéntico sentido, por todas, Sentencia del Tribunal Supremo de 18 de marzo de 1999 [...] Todo ello por las razones que más «in extenso" se dicen en la Sentencia de 15 de noviembre de 1993, ya citada, y que, en resumen, se basan en la necesaria garantía del ciudadano, lo que implica que para su virtualidad práctica, en los supuestos de actuación de varias Administraciones, será necesaria una solución de solidaridad que opere en el ámbito externo de la relación del ciudadano con la Administración, independien-

\footnotetext{
3 Véase RJ 2003\183.

4 Véase ECLI:ES:TSJM:2016:2251.

5 Véase JUR 2007\90857.
} 
temente de que en el aspecto interno de la relación de las Administraciones, las circunstancias de cada caso concreto permitan la imputación a una o a todas, con cuantificaciones de la participación.

Por tanto, cuando una Administración resulta condenada al pago de la correspondiente indemnización frente a un particular, podrá ejercitar la correspondiente acción de regreso o de repetición frente aquellas otras que han concurrido a la producción del hecho dañoso ${ }^{6}$.

En este sentido, hay que indicar, a su vez, que, en el caso de deudas solidarias en las que no sea posible establecer el porcentaje de responsabilidad de cada uno de los deudores, habrá de aplicarse la presunción de mancomunidad o el abono por partes iguales, tal como ha venido a concluir el Tribunal Supremo, en su sentencia de 21 de febrero de $2020^{7}$ :

PRIMERO.- [...] En estas circunstancias ha de considerarse justificada la reclamación por partes iguales efectuada por la Administración autonómica, que efectuó el pago íntegro de la deuda, a las demás administraciones declaradas responsables solidarias, en cuanto resulta conforme con los términos en que se declaró la responsabilidad solidaria, de los que no resulta ni cabe discernir con certeza una distribución distinta de la responsabilidad entre las Administraciones intervinientes, que tampoco se concreta por los Ayuntamientos que se oponen a ello, por lo que debe operar la presunción de imputación por partes iguales establecida en el art. 1138 del Código Civil [...].

Además, este mismo pronunciamiento zanja la posible duda que pudiera plantearse sobre otro extremo de particular relevancia, al indicar que será la jurisdicción contencioso-administrativa la que, en todo caso, ha de conocer de cualquier controversia que pudiera surgir en el ejercicio de la acción de regreso por alguna de las partes.

La acción de repetición ha de deducirse en vía contencioso-administrativa en tanto implica a tres Administraciones Públicas, tiene su origen en una sentencia del Orden Jurisdiccional Contencioso en relación con actuaciones administrativas y su finalidad es el cobro de una cantidad — ya satisfecha por una de las tres Administraciones concernidas-, a cuyo pago fueron condenadas, en concepto de indemni-

6 Véase, en relación con la institución jurídica de la acción de regreso, J. Barcelona Llop (2000), «La acción de regreso en la Ley de Régimen Jurídico de las Administraciones Públicas y del Procedimiento Administrativo Común", Revista Española de Derecho Administrativo, 105, págs. 37-57; J. Junceda Moreno (2014), «La acción de repetición o regreso en materia de responsabilidad en el ámbito municipal», La administración práctica: enciclopedia de administración municipal, 5, págs. 61-66; C. Saura Fructuoso (2015), «La ignota acción de regreso de la administración en la era de la transparencia, la eficiencia y la responsabilidad», Documentación Administrativa, 2.

7 Véase ECLI:ECLI:ES:TS:2020:528. 
zación de daños y perjuicios causados por un acto administrativo (reclasificación de un suelo) lesivo a los intereses de sus propietarios.

\section{LA RECLAMACIÓN DE RESPONSABILIDAD PATRIMONIAL COMO MECANISMO PARA RESARCIR LOS DAÑOS QUE UNA ADMINISTRACIÓN CAUSA A OTRA EN EL ÁMBITO URBANÍSTICO}

\section{LA DISCUSIÓN ACERCA DE LA LEGITIMACIÓN PARA EL EJERCICIO DE LA ACCIÓN}

Habiéndose admitido un régimen de responsabilidad solidaria frente a los particulares, no parece comprensible que pueda llegar a excluirse la posibilidad de reconocer legitimación para el ejercicio de la acción de responsabilidad patrimonial de una Administración frente a otra por daños de carácter urbanístico.

Este planteamiento, sin embargo, es combatido por el Consejo de Estado, entre otros, en su Dictamen 92/2001, de 22 de febrero, negando esa acción, con carácter general, para todos aquellos supuestos en los que la Administración pública reclamante no actúe como un simple particular o usuario de un servicio público:

Cuando una Administración Pública actúa en el ejercicio de potestades públicas en las relaciones jurídicas donde la responsabilidad de otra Administración se cuestiona, no puede considerarse como simple «usuaria» de un servicio público y por ello asimilarse a un particular, administrado o beneficiario afectado por el buen o mal funcionamiento de dicho servicio.

En definitiva, entiende este alto órgano consultivo que resulta difícil de justificar la legitimación cuando una Administración ha actuado en los hechos que están en el origen de la reclamación desde una posición activa, como persona de derecho público y no como sujeto pasivo de una lesión que le haya sido directamente inferida ${ }^{8}$.

8 Véase Dictamen de 27 de junio de 2019 (expte. 345/2019) y Dictamen de 22 de febrero de 2001 (expte. 92/2001). Semejante doctrina se ha establecido en los supuestos relativos a reclamaciones económico-administrativas de actos tributarios de las entidades locales (así, en el Dictamen 358/97, de 5 de junio) y en el caso de la reclamación de responsabilidad del Estado legislador instada por el Ayuntamiento de Valencia, por la pérdida patrimonial derivada de la declaración de inconstitucionalidad del art. 59 del texto refundido de la Ley sobre el Régimen Jurídico del Suelo y Ordenación Urbana, aprobado por Real Decreto Legislativo 1/1992, de 26 de junio, acordada en Sentencia del Tribunal Constitucional 61/1997. En la esfera urbanística, este mismo planteamiento se acoge en FD sexto y no- 
Sin embargo, el Tribunal Supremo, en sentencia de 16 de marzo de 2016, ha rebatido explícitamente esa doctrina y ha desautorizado su uso por los tribunales de instancia, en particular, al ocuparse de los daños producidos con motivo de la gestión compartida de ciertos tributos, como el Impuesto sobre Bienes Inmuebles, proclamando que no existe un principio general de inmunidad en el ámbito de las relaciones interadministrativas?:

La sentencia de instancia [...] declara [que] ha de destacarse el dictamen emitido por el Consejo de Estado en fecha 9 de mayo de 2.013, en el que se viene a concluir de la siguiente forma literal: «[...] el Ayuntamiento de Pego, al reclamar una indemnización por lo dejado de recaudar en el Impuesto sobre Bienes Inmuebles, actúa como persona jurídica pública, no ajena —en cuanto entidad local—al proceso de elaboración de las ponencias de valores y destinataria de la recaudación de dicho impuesto» [...] No obstante esa referencia [...] Esa gestión compartida no es relevante para excluir esa responsabilidad, al menos en el ámbito de las relaciones interadministrativas, porque ambas fases están perfectamente delimitadas y nada impide que en esa relación interadministrativa puedan surgir supuestos generadores del daño antijurídico que, si concurren los demás presupuestos de la institución, puedan generar responsabilidad.

A su vez, en contra de ese criterio no pueden resultar más expresivas las SSAN de 17 de abril de $2013^{10}, 20$ de enero de $2006^{11}$ y 25 de febrero de $2005^{12}$, que, igualmente, en referencia directa a los dictámenes emitidos por el Consejo de Estado, vienen a concluir en favor de la imposibilidad de aplicar una interpretación restrictiva en este punto, excluyendo que deba negarse legitimación activa a una Administración a la hora de reclamar responsabilidad patrimonial frente a otra, por el simple hecho de que la lesión o el daño sufrido sean con motivo del ejercicio de una potestad administrativa o pública:

La resolución impugnada, siguiendo lo dictaminado por el Consejo de Estado, considera que, si bien es cierto que pueden subsumirse bajo el concepto de «particulares» a los Ayuntamientos, ello es así cuando se trata de simples usuarios de servicios públicos, pero no cuando ejercen potestades administrativas como es el caso que nos ocupa (potestad tributaria), lo que determinaría, según la propia resolución impugnada, la inadmisibilidad de la reclamación por falta de legitimación

veno, de la Sentencia 380/2020, de 1 de diciembre de 2020, del TSJ de Cantabria (rec. 296/2018).

9 Véase ECLI:ES:TS:2016:1120. En relación con este pronunciamiento, véase J. Fernández-Corredor Sánchez-Diezma (2016), "Responsabilidad patrimonial de una Administración pública frente a otra (Comentario a la STS de 16 de marzo de 2016)», CEFLegal: revista práctica de derecho. Comentarios y casos prácticos, 185, págs. 187-192.

10 Véase ECLI:ES:AN:2013:1581.

11 Véase ECLI:ES:AN:2006:4619.

12 Véase ECLI:ES:AN:2005:1160. 
activa del Ayuntamiento [...] Sin embargo, no es éste el criterio de la Sala que, en sintonía con el manifestado en numerosas ocasiones por el Tribunal Supremo (por todas, STS de 8 de junio de 2000), entiende que debe integrarse la laguna existente en el Ordenamiento Jurídico y naturalmente entender subsumidos dentro de la expresión "particulares» también a los distintos entes públicos de la Administración sin restricción de ningún tipo, por lo que ninguna dificultad existe en entender legitimado en el presente caso al Ayuntamiento recurrente [...] En conclusión, no cabe negar en este caso y en aplicación de la anterior doctrina la legitimación al Ayuntamiento de Córdoba.

Cabe igualmente traer a este lugar la SAN de 26 de julio de $2004^{13}$, que incide en la posibilidad de que surja responsabilidad patrimonial de una Administración frente a otra, en los supuestos en los que estas ejercitan competencias compartidas entre sí, pero con ámbitos funcionales perfectamente diferenciados:

Los hechos que se encuentran en el origen del presente recurso son los que siguen: El Ayuntamiento actor solicitó indemnización de daños y perjuicios, pues no pudo exacionar el IBI de las presas y saltos de agua al no haber sido previsto por el Estado y asignado el correspondiente valor catastral, atribuyendo la minoración de ingresos locales correspondiente a las cuotas de 1990 a 1992, a la inactividad del Estado, y solicitando la correspondiente indemnización [...]. La legitimación activa de la Corporación Local demandante es incuestionable a partir de la doctrina jurisprudencial emanada entre otras de la sentencia de la Sala $3^{\text {a }}$, Sección $6^{\mathrm{a}}$ del Tribunal Supremo de 24 de Febrero de 1994.

Idéntica doctrina se recoge en la sentencia de este mismo Tribunal, de 5 de febrero de 2013, en la que, nuevamente, se analiza un supuesto en el que la inactividad de una Administración o su actuación descuidada genera un daño patrimonial a otra en el ámbito de una relación interadministrativa, en el que ambas ejercen poderes públicos ${ }^{14}$ :

La aplicación de las normas acabadas de mencionar a los hechos anteriores determina la procedencia de la reclamación del Ayuntamiento [...], por cuanto que la Gerencia catastral actuó de forma descuidada al omitir la notificación individual del valor catastral a que venía obligada o, más bien, al no comprobar que dicha notificación se había realizado correctamente [...] A esta conclusión no puede oponerse eficazmente la alegación del Abogado del Estado que se basa en las relaciones de cooperación entre las dos Administraciones, la local y la del Estado, en lo relativo al impuesto y la obligación de colaboración, lo que obligaría a cada una de ellas a soportar las consecuencias de los actos respectivos, quedando así excluida la antijuridicidad del daño, pues, si bien es cierto que existe un deber general de

13 Véase ECLI:ES:AN:2004:5399.

14 Véase ECLI:ES:AN:2013:948; un supuesto casi idéntico, referido al Ayuntamiento de Manresa, puede verse en SAN 276/2019, de 16 mayo [ECLI:ES:AN:2019:2173]. 
colaboración con el Catastro [...] no lo es menos que las competencias de cada Administración vienen claramente diferenciadas.

En fin, y sin ánimo de exhaustividad, en el mismo sentido se han pronunciado los tribunales superiores de justicia, que proclaman la posibilidad de exigir, sin restricción alguna, responsabilidad patrimonial en el ámbito de las relaciones interadministrativas, al no eximir nuestro ordenamiento de esa obligación, ni fijar mecanismo alternativo alguno para hacer efectivo el resarcimiento de ese daño.

Al respecto, señala la STSJ de Andalucía, de 27 de marzo de $2018^{15}$, que:

Comenzando con la cuestión concerniente a la legitimación activa ciertamente no cabe desconocer que son muy distintos los principios que rigen las relaciones entre Administración Pública y particulares de los aplicables en las relaciones entre dos o más Administraciones Públicas, dotadas de idénticas o similares potestades o prerrogativas. Sin embargo nuestro Tribunal Supremo ya ha tenido ocasión de pronunciarse al respecto concluyendo en la posibilidad que asiste a la Administración Pública de exigir sin restricciones responsabilidad patrimonial en el ámbito de las relaciones interadministrativas [...] ni está excluida la obligación de resarcir los daños en tales relaciones ni nuestro Derecho establece mecanismo alguno para hacerlos efectivos.

E, igualmente, la STSJ del País Vasco de 16 de marzo de $2007^{16}$ rechaza que, en base a los principios de cooperación y solidaridad, exista un hipotético deber de soportar en estos casos los riesgos inherentes a la acción de otras Administraciones públicas:

Deviene manifiestamente disconforme a derecho la Orden Foral objeto de impugnación, que, sin entrar a resolver sobre el fondo de las reclamaciones planteadas, las inadmite por carecer el Ayuntamiento de Donostia-San Sebastián de legitimación para ejercitar acciones de responsabilidad patrimonial, al actuar en el ejercicio de potestades administrativas, invocando los principios de cooperación y solidaridad que rigen las relaciones de las Administraciones Públicas, que obligan a cada una de ellas a soportar los riesgos nacidos de la prestación de los servicios públicos por otras [...] Por el contrario, en virtud de la interpretación integradora del término "particulares» que se propugna en la sentencia de 14 de octubre de 1994, no puede negarse al Ayuntamiento de Donostia-San Sebastián acción frente a la Diputación Foral de Gipuzkoa, que viene por ello obligada a iniciar los procedimientos pertinentes, dando curso a las solicitudes deducidas por la parte actora, en los que se dilucide si concurren los requisitos exigidos para declarar la responsabilidad patrimonial pretendida.

15 Véase ECLI:ES:TSJAND:2018:5100.

16 Véase JUR 2007\137048. 
Mutatis mutandis, esta doctrina judicial, alumbrada — según cabe apreciar- en la esfera tributaria, entendemos que resulta igualmente trasladable a otros muchos ámbitos materiales y, en particular, al urbanístico.

Por tanto, no debe negarse legitimación a una Administración para reclamar frente a otra el resarcimiento de un daño patrimonial, por el hecho de que este se produzca como consecuencia del ejercicio de una potestad pública compartida, ya que, incluso en estos supuestos, cada una de esas Administraciones puede actuar, al mismo tiempo, como sujeto pasivo de la prestación de un servicio público del que es titular la otra, y en cuyo desempeño puede generarse, perfectamente, un daño antijurídico.

Además, en determinados ámbitos, como el urbanismo, esos daños no solo pueden generarse entre las distintas Administraciones que, de forma concurrente, ejercitan una misma o análoga potestad pública, sino que, a veces, pueden venir producidos por la acción o pasividad de otras Administraciones u organismos públicos, que emiten informes sectoriales o dotan de ciertas infraestructuras a un territorio, jugando así un papel relevante, aunque indirecto, en la aprobación de determinados instrumentos de ordenación.

\section{EL PLAZO DE PRESCRIPCIÓN PARA FORMULAR LA CORRESPONDIENTE RECLAMACIÓN POR DAÑOS: LA APLICACIÓN A ESTOS SUPUESTOS DE LA TEORÍA DE LA «ACTIO NATA»}

Al margen de la legitimación para el ejercicio de la acción, el plazo para solicitar el inicio del procedimiento de responsabilidad patrimonial se erige en el primero de los presupuestos que han de ser examinados.

En relación con ese segundo extremo, dispone el art. 67 de la LPACAP que en los casos en que proceda reconocer derecho a indemnización por la anulación en vía administrativa o contencioso-administrativa de un acto o disposición de carácter general, el derecho a reclamar prescribirá al año de haberse notificado la resolución administrativa o la sentencia definitiva ${ }^{17}$.

Así pues, puede entenderse como cuestión pacífica que, en el caso de la anulación de un plan urbanístico, el plazo de prescripción para reclamar, entre

17 Respecto de la prescripción de la acción en materia de responsabilidad patrimonial, véase T. Cano Campos (2019), «El comienzo del plazo para reclamar los dańos causados por la Administración: el tópico de la "actio nata»", Revista de Administración Pública, 210, págs. 175-216; R. Perera Mezquida (2019), «Teoría de la actio nata y la interrupción del plazo de prescripción en materia de responsabilidad patrimonial», en F.J. Bauzá Martorell (coord.), Doctrina consultiva: a propósito del 25 aniversario del Consejo Consultivo de las Illes Balears, págs. 689-712; C. Romero Rey (2011), «Dies a quo para el cómputo del plazo de prescripción de las acciones de responsabilidad patrimonial derivadas de la anulación jurisdiccional de un acto o disposición administrativa", Actualidad Administrativa, 8, págs. 1 y ss. 
otros, los gastos generados por la elaboración de este instrumento o cualquier otro daño que se derive, automáticamente, de su anulación, deberá computarse a partir de la fecha de comunicación de la sentencia judicial que dé firmeza a ese pronunciamiento.

Ahora bien, podrían darse ciertos casos en los que este principio general pudiera verse abocado a una cierta modulación. En este sentido, otro de los conceptos relevantes que genera un particular perjuicio en el patrimonio de la Administración es la posibilidad de tener que resolver los convenios urbanísticos ligados a la tramitación del plan urbanístico, una vez anulado este.

En tales supuestos, cabe advertir una cierta singularidad en relación con la aplicación de la teoría de la actio nata, pudiendo entenderse que el plazo concedido al efecto por el citado art. 67 de la LPACAP ha de computarse no desde la notificación de la anulación definitiva del PGOU, sino desde la fecha en la que la Administración demandante se ve forzada a adoptar el acuerdo de resolución del convenio urbanístico, por quedar este despojado de la necesaria cobertura jurídica.

Resulta así que, hasta que no se ejercita la acción por incumplimiento contractual, en base al art. 1.124 del CC y tiene lugar la estimación de la resolución del convenio por el órgano municipal competente, no surge el perjuicio o quebranto económico para la Administración pública. De hecho, cabría que la Administración que ha suscrito el convenio resuelva en contra de lo solicitado, conduciendo a que dicho conflicto se dirima finalmente ante la jurisdicción contencioso-administrativa. Pero es que, además, la anulación del PGOU podría no conducir indefectiblemente a la resolución del convenio urbanístico, toda vez que el perjudicado podrá escoger entre la resolución de la obligación o el cumplimiento, con resarcimiento de daños y abono de intereses en ambos casos.

Sobre la aplicación del art. 1.124 del CC a estos supuestos, resulta expresiva, entre otras, la STSJ de Canarias de 19 de enero de 2009, en la que se pone de relieve que una eventual reclamación de responsabilidad patrimonial por este motivo solo es posible una vez sustanciado el procedimiento previo para pronunciarse acerca de la resolución del convenio ${ }^{18}$ :

No existe error alguno de la juzgadora al rechazar la reclamación por responsabilidad patrimonial, pues la acción ejercitada era la del artículo 1.124 del CC, sin que pueda entenderse que se ejercitaba una acción de responsabilidad patrimonial por cuanto dicha acción tiene un procedimiento administrativo previo y necesario, es decir, no se puede ejercitar frente al acto que deniega la resolución de un convenio urbanístico sino que es ejercitable a consecuencia de dicha denegación y tras el procedimiento administrativo contemplado en la LRJPAC.

18 Véase ECLI:ES:TSJICAN:2009:1050. 
Al margen de esa circunstancia, en la mayor parte de los ordenamientos autonómicos, rigen a efectos de determinar las consecuencias del incumplimiento de un convenio urbanístico, en primer lugar, las propias estipulaciones de este y, solo si no las hubiera, deberá acudirse, con carácter supletorio, a la referida vía de la responsabilidad patrimonial.

Así lo ha admitido, además, el Tribunal Superior de Justicia de Cantabria, en Sentencia de 22 de febrero de $2016^{19}$, en la que señaló lo siguiente:

La conclusión legal obligada es la de regir las consecuencias del presunto incumplimiento por parte del ayuntamiento, exclusivamente de la forma fijada por las partes en el artículo $6^{\circ}$ de su convenio. Tal y como se ha pronunciado anteriormente esta Sala: «La responsabilidad de la administración hacia el particular que suscribe un convenio urbanístico en caso de incumplimiento es una responsabilidad contractual (SSTS de 17 de noviembre de 2003, recurso de casación n 1827/2001 y de 3 de abril de 2001, recurso de casación no 8856/1996) con lo que significa en cuanto a la responsabilidad patrimonial o extracontractual ejercitada por medio del presente recurso contencioso administrativo, lo cual ha venido a ser confirmado posteriormente por el art. 263 LOTRUS (Ley de Cantabria 2/2001 de 25 de junio).

En la misma línea, se pronunció ese tribunal en su sentencia de 20 de febrero de 2014, indicando que el plazo de prescripción, en los supuestos de ejercicio de una acción de responsabilidad patrimonial contractual, no es el de un ańo, sino los cuatro años que fija actualmente la Ley General Presupuestaria ${ }^{20}$ :

La responsabilidad de la administración hacia el particular que suscribe un convenio urbanístico en caso de incumplimiento es una responsabilidad contractual [...] Ello conlleva importantes consecuencias, entre ellas, el plazo de ejercicio de la demanda; la consideración de la cualidad de responsabilidad contractual da lugar a que los tribunales consideren que no opera el plazo de prescripción de un ańo para los supuestos de responsabilidad extracontractual, sino el de prescripción de cinco años por aplicación de la Ley General Presupuestaria de aplicación a los supuestos de responsabilidad contractual, plazo actualmente de cuatro ańos, en aplicación de la disposición derogatoria única de la Ley 47/2003 de 26 de noviembre General Presupuestaria.

Igualmente, sobre la aplicación en estos casos del plazo de prescripción de cuatro años, se pronuncia, entre otras muchas, la STSJ de Andalucía de 7 de diciembre de $2017^{21}$ :

Así las cosas y en cuanto al plazo de prescripción del derecho a reclamar el cumplimiento de las obligaciones asumidas por las partes en el convenio urbanístico

19 Véase ECLI:ES:TSJCANT:2016:289.

20 Véase ECLI:ES:TSJCANT:2016:289.

21 Véase ECLI: ES:TSJAND:2017:14892. 
- o, lo que es igual, para la efectividad de la denominada responsabilidad contractual—, devienen aquí aplicables los plazos prescriptivos que contempla la Ley 47/2003, de 26 de noviembre, General Presupuestaria [...] norma específica del ordenamiento jurídico administrativo que excluye la ausencia de previsión legal que autorizaría la aplicación supletoria del CC y, en consecuencia, el plazo prescriptivo de quince ańos previsto en el artículo 1964 de este último Cuerpo legal que postula la apelante.

Por tanto, cuando un interesado insta la resolución de los convenios urbanísticos suscritos con la Administración, puede, o bien ejercitar una acción de responsabilidad patrimonial o una acción de incumplimiento contractual en base al art. 1.124 del Código Civil; en cuyo caso dispone de cuatro años para entablar la misma, por lo que, difícilmente, la Administración pública que sufre el consiguiente perjuicio patrimonial debe verse compelida a formular su reclamación por daños en el plazo de un año desde la notificación de la anulación del PGOU. Ello nos lleva a sostener que, ante una casuística tal, la Ley 39/2015 presenta una clara laguna jurídica que, o bien ha de ser debidamente cubierta por el legislador, o debería conducir a una reinterpretación por los Tribunales de Justicia del apdo. 1, del art. 67 de dicha ley, toda vez que el efecto lesivo de la anulación del plan no se manifiesta en determinados casos, hasta tiempo después de producirse ese hecho.

\section{LA CONCURRENCIA DE LOS REQUISITOS DE FONDO PARA QUE SURJA EL DEBER DE RESARCIR LOS DAÑOS}

\subsection{El daño o lesión patrimonial}

Anulado un plan urbanístico, la tramitación de uno nuevo debe producirse desde el inicio y acomodarse, por tanto, a la realidad que subyazca en ese momento, toda vez que la anulación del anterior instrumento opera con efectos ex tunc.

Por otra parte, si la causa que origina la anulación del plan es externa al mismo y no supone un mero defecto formal, intrínseco a su tramitación ${ }^{22}$, es posible que la ordenación y la clasificación del suelo que sirvió de base para los nuevos desarrollos urbanísticos decaigan de igual modo.

Eso hará que el nuevo plan, probablemente, deba configurarse a partir de un modelo urbanístico distinto, que se someterá a la correspondiente evaluación ambiental y a los oportunos trámites de información pública, sin que pueda darse validez a todo lo tramitado hasta entonces. Ello sin perjuicio, además, de los problemas y retrasos —o de la imposibilidad misma - de subsanar los motivos determinantes de la anulación de ese instrumento, que condicionarán igualmente

22 Véase ECLI:ES:TS:2016:4838. 
el planteamiento urbanístico de partida. En definitiva, es difícil pensar que un documento de la complejidad de un plan urbanístico pueda servir de algo, transcurridos una serie de ańos, simplemente, guardado en un cajón.

Pues bien, tal y como ya apuntamos, uno de los principales perjuicios patrimoniales que puede sufrir la Administración urbanística deriva del hecho mismo de que los gastos de redacción del plan devengan inútiles tras la anulación de este. Gastos cuya cuantía puede llegar a ser muy elevada, ya que, habitualmente, la elaboración de un plan suele encargarse a equipos externos y su tramitación se prolonga en el tiempo, en virtud de la complejidad de este tipo de procedimientos, que incluye diversas fases de información pública y la pertinente tramitación ambiental separada ${ }^{23}$.

La inutilidad de los trabajos realizados irrogaría un daño efectivo, que vendría a incidir negativamente en el patrimonio de la Administración autora del plan, de forma real y actual. No se trataría, por tanto, de un dańo futuro o meramente hipotético, sino que la lesión que se produce surge automáticamente desde el mismo momento en que se dicta la sentencia anulatoria recaída y esta deviene firme.

Además, sería un daño perfectamente evaluable desde el punto de vista económico, equivalente al precio abonado al equipo redactor del PGOU por la ejecución de esos trabajos ${ }^{24}$. E, igualmente, sería un daño individualizable, que afecta a un sujeto concreto, la Administración autora del plan, que es quien habitualmente asume esos costes, de forma exclusiva, con cargo a sus presupuestos.

Por tanto, siempre que concurran los demás requisitos que emanan de la institución jurídica de la responsabilidad patrimonial, una Administración pública, autora de un plan urbanístico, puede llegar a encontrarse en una posición jurídica equivalente a la de un ciudadano que, tras promover la tramitación del mismo, ve decaer sus efectos como consecuencia de la anulación posterior de un instru-

23 Acerca del alto coste económico y de la complejidad que encierra la tramitación de un PGOU, véase: https://www.diariosur.es: «Marbella avanza en la hoja de ruta diseńada hace ya cuatro años para recuperar la normalización urbanística tras la anulación del Plan General de Ordenación Urbana (PGOU) de 2010 [...] El trabajo, en el que inicialmente se ha previsto que se inviertan tres ańos y medio ( 42 meses), costará a las arcas municipales más de dos millones de euros. El precio base se ha fijado en 2.400.125,93 euros». En sentido similar, https://www.eldiario.es: «La Junta de Gobierno Local ha autorizado esta semana a los servicios jurídicos municipales para iniciar las acciones judiciales, que deberán sustanciarse ante el Tribunal Superior de Justicia de Cantabria —en el caso de las dirigidas contra el Gobierno regional y la CHC_ y ante la Audiencia Nacional —en lo que respecta al Ministerio— - ... ] La reclamación asciende a 3.084.604 euros —-más intereses—, y se corresponde con el importe invertido en la redacción del documento urbanístico, un proceso que «requirió más de ocho años de trabajo e incluyó cuatro periodos de exposición pública».

24 Véase A. L. Vidal Alonso (2019), "Aproximación al concepto de perjuicio patrimonial», Revista de Estudios de la Justicia, 30, págs. 111-149; S. González-Varas Ibáñez (2017), «Presupuestos de la responsabilidad patrimonial de las administraciones públicas en la LRJSP 40/2015», Actualidad Administrativa, 5. 
mento jurídico que le servía de cobertura, sufriendo, en consecuencia, una grave lesión patrimonial, que ha de ser resarcida.

Del mismo modo, cabría añadir que, cuando la anulación de un PGOU derive en la resolución de los convenios urbanísticos suscritos por la Administración autora del mismo, también se irroga a esta un daño emergente o lesión patrimonial, consistente en la pérdida del importe económico con el que se haya tenido que resarcir a las partes firmantes del citado instrumento.

Estos convenios (de planeamiento o de gestión) constituyen una particular fuente de ingresos para las entidades locales, como consecuencia de la recuperación de las plusvalías generadas por la patrimonialización de nuevos aprovechamientos urbanísticos que genera la aprobación del plan y que se truncan con su anulación $^{25}$. En este caso, ese daño surge desde el mismo momento en que se adopte el acuerdo de resolución del convenio, como consecuencia de la reclamación presentada por el particular o la entidad mercantil que suscribió el mismo, por los cauces que anteriormente hemos dejado expuestos. Ese daño sería equivalente al importe en el que la Administración ve mermado su patrimonio al tener que indemnizar por la cantidad percibida en concepto de plusvalía o de las contraprestaciones percibidas, sin obtener nada a cambio.

\subsection{La antijuridicidad del daño: la «irracionalidad» en el actuar de la Administra- ción frente a la que se dirige la acción}

Tal como ha acuñado la doctrina judicial, solo ciertas ilegalidades causantes de la anulación de un acto o disposición administrativa convierten el daño en antijurídico $^{26}$. Así lo indica, entre otras muchas, la SAN 1673/201427, que, con abundante referencia a la doctrina del Tribunal Supremo, recuerda lo siguiente:

25 Véase, entre otras, STSJ de Castilla y León 246/2016, de 25 de noviembre de 2016 [JUR 2017\5759], por la que se declara resuelto, por imposibilidad de cumplimiento, el convenio urbanístico suscrito con el Ayuntamiento de Ávila, al que se condena a indemnizarla en la cantidad de 1.247.729,93 euros, más los intereses legales desde el 21 de enero de 2006 hasta su completo pago; Sentencia 205/2018, de 17 de diciembre de 2018, del JCA núm. 1 de Cartagena, por la que se declara la resolución del Convenio Urbanístico de 12 de julio de 2.005, condenando al Ayuntamiento de Cartagena a la devolución de la cantidad de 5.224.706 euros, más los intereses legales desde el nacimiento del silencio administrativo originado por la no resolución expresa de la petición de 15 de diciembre de 2016 y hasta su efectivo pago [RJCA 2018\1502].

26 Véase T. R. Fernández (2018), «Existe un deber jurídico de soportar los perjuicios producidos por un acto administrativo declarado nulo por sentencia firme?», Revista de Administración Pública, 205, págs. 221-237.

27 Véase ECLI:ES:AN:2014:1673. En la doctrina, véase L. Medina Alcoz (2005), «El resarcimiento del daño causado por acto administrativo ilegal: Análisis de la cuestión en los ordenamientos italiano, francés, alemán y español», Revista General de Derecho Administrativo, 9. 
La antijuridicidad, como requisito del daño indemnizable, no viene referida al aspecto subjetivo del actuar antijurídico de la Administración, sino al objetivo de la ilegalidad del perjuicio, en el sentido de que el interesado tenga el deber jurídico de soportarlo, ya que, en tal caso, desaparecería la antijuridicidad de la lesión al existir causas de justificación en el productor del daño, esto es, en el actuar de la Administración [...]; así, el Alto Tribunal condiciona la exclusión de la antijuridicidad del daño a la existencia de un deber jurídico de soportarlo, es decir, a que la actuación de la Administración se mantenga en unos márgenes de apreciación no sólo razonables sino razonados.

En base a esta doctrina, se concluye que cuando la actuación desplegada, además de ilegal, resulta ilógica, arbitraria o irrazonable, el daño causado debe considerarse antijurídico y, al respecto, el análisis que habrá de realizarse deberá tener lugar a la luz del caso concreto, discriminándose en función de cuál sea el motivo que ha conducido a la anulación del plan.

Decíamos al comienzo que los dańos que derivan de la anulación de un plan no solo pueden generarse entre las distintas Administraciones que, de forma concurrente, ejercitan la potestad pública urbanística; sino que, a veces, pueden venir producidos por la acción o pasividad de otras Administraciones u organismos públicos, que emiten informes sectoriales o dotan de ciertas infraestructuras a un territorio, jugando así un papel relevante en la aprobación de determinados instrumentos de ordenación.

Por tanto, cuando el motivo de la anulación de un plan sea una causa intrínseca a este, habrá que verificar cuál ha sido la actuación de las Administraciones intervinientes en el procedimiento que condujo a su aprobación. En cambio, cuando la anulación del plan obedezca a una causa externa al mismo, el examen de la actuación desplegada deberá centrarse, con carácter prioritario, en el ejercicio de aquellas otras potestades públicas que sirvieron de presupuesto para la elaboración del citado instrumento, y que, a su vez, se erigen en causa de la posterior anulación de este.

En ambos supuestos resulta de aplicación la doctrina del Tribunal Constitucional en relación con la fundamentación jurídica de las resoluciones o acuerdos que emiten los poderes públicos.

$\mathrm{Al}$ respecto, señala ese órgano jurisdiccional, en su sentencia de 23 de junio de $2014^{28}$, que la falta de motivación, por su carencia total o cuando esta es insuficiente, conduce a la arbitrariedad e irrazonabilidad de la resolución recaída:

[...] Este Tribunal viene expresando reiteradamente que la motivación consiste en la expresión de los criterios esenciales de la decisión o, lo que es lo mismo, su ratio decidendi (SSTC 119/2003, de 16 junio; 75/2005, de 4 abril, y 60/2008, de 26 mayo), por lo que se produce infracción... cuando no hay motivación — por carencia total一, o es insuficiente, pues está desprovista de razonabilidad, desco-

28 Véase RTC 2014\102, FD Quinto. 
nectada con la realidad de lo actuado. Del mismo modo, hemos afirmado que 'la arbitrariedad e irrazonabilidad se producen cuando la motivación es una mera apariencia. Son arbitrarias o irrazonables las resoluciones carentes de razón, dictadas por puro capricho, huérfanas de razones formales o materiales y que, por tanto, resultan mera expresión de voluntad (STC 215/2006, de 3 de julio), o, cuando, aun constatada la existencia formal de la argumentación, el resultado resulte fruto del mero voluntarismo (STC 248/2006, de 24 de julio).

A su vez, el Tribunal Supremo, en sentencia de 13 de julio de $1984^{29}$, ya abordó la distinción entre una motivación suficiente pero discutible y la llamada «sit pro rationes voluntas»:

Nunca es permitido confundir lo discrecional con lo arbitrario, pues que aquello se halla o debe hallarse cubierto por motivaciones suficientes, discutibles o no, pero considerables en todo caso; y no meramente de una calidad que los haga inatacables, mientras que lo segundo, o no tiene motivación respetable, sino — pura y simplemente - la conocida "sit pro rationes voluntas» o la que ofrece lo es tal que, escudriñando su entraña, denota, a poco esfuerzo de contrastación, su carácter de realmente indefinible su inautenticidad.

En el mismo sentido se pronuncia la STSJ de Andalucía de 25 de septiembre de 2017, que alude a la indefensión que la falta de motivación puede producir en los interesados ${ }^{30}$ :

Todo lo señalado, pone de manifiesto, además de la nulidad radical de la modificación de elementos aprobada, una absoluta falta de motivación, que la convierte en arbitraria (artículo 54 Ley 30/92) y anulable por la indefensión que ocasiona, conforme dispone el artículo 63 Ley 30/92.

Y, sin ánimo de exhaustividad, la STSJ de Castilla-La Mancha de 21 de mayo de 2001 vuelve a equiparar la insuficiente motivación de los actos administrativos, con la actuación arbitraria de los poderes públicos ${ }^{31}$ :

Se han infringido de esta manera por la Administración demandada los artículos 54 y 89 de la Ley 30/92, de Régimen Jurídico de las Administraciones Públicas y del Procedimiento Administrativo Común, que obligan a los órganos administrativos [...] a motivar sus resoluciones. La falta total de motivación de la resolución administrativa recurrida equivale a una motivación arbitraria y debe dar lugar a la declaración de la nulidad de la misma.

\footnotetext{
29 Véase RJ 1984\4673.

30 Véase ECLI: ES:TSJAND:2017:14709.

31 Véase ECLI:ES:TSJCLM:2001:1629I.
} 
En definitiva, la falta de motivación de los acuerdos comporta que la Administración no solo actúe fuera de la legalidad, sino que, además, ejerza sus facultades de forma desproporcionada y apartándose en su actuar de los parámetros establecidos en la norma. En esos casos no cabe entender que la actuación desplegada por la Administración se haya enderezado a satisfacer los fines para los que se la ha atribuido la potestad que ha venido a ejercitar. Al contrario, nos hallaríamos ante una actuación descuidada, que no atiende a los estándares que cabe esperar de una Administración pública llamada a satisfacer los intereses generales.

\subsection{Títulos de imputación del daño}

En orden a la imputación del daño pueden operar igualmente distintos títulos jurídicos, en atención a la causa o motivo que determine la anulación del planeamiento.

En ocasiones, esa imputación puede venir atribuida a la Administración regional en base a la competencia que esta ostenta en materia urbanística, al ser con frecuencia esa Administración la que aprueba definitivamente los PGOU y, por ende, lleva a cabo el correspondiente control de legalidad de estos instrumentos ${ }^{32}$.

Otras veces, como ya anunciamos, los títulos de imputación de la posible responsabilidad patrimonial pueden obedecer al ejercicio de competencias ajenas al urbanismo, pero que tangencialmente inciden, a su vez, en la tramitación del planeamiento o pueden afectar de algún modo a la validez de este. La intervención lesiva de esos entes públicos puede tener lugar, por tanto, en la actividad que estos despliegan en materia de espacios naturales, costas, carreteras, aguas, obras públicas o medio ambiente, entre otras; que, en unos casos, lleva a cabo la Administración del Estado o sus organismos autónomos y, en otros, la propia Administración autonómica.

En cada uno de estos supuestos la anulación del planeamiento suele producirse por un funcionamiento anormal del servicio público por parte de esas Administraciones, al concurrir culpa o negligencia en la conducta causante de ese daño. Al respecto, la STS de 19 de julio de $2010^{33}$ señala que la anormalidad en el servicio no debe necesariamente estar conectada a la existencia de una infracción subjetiva de los deberes de los funcionarios, sino que basta con demostrar que objetivamente existió una deficiencia (aun cuando fuera aislada), determinante del perjuicio causado.

Igualmente, la doctrina y la jurisprudencia utilizan un concepto muy amplio de servicio público, que abarca cualquier actuación administrativa en el ejercicio de una potestad pública, e incluso los actos derivados de la acti-

32 Véase STSJ de Madrid 105/2016, de 2 marzo [ECLI:ES:TSJM:2016:2251].

33 Véase ECLI:ES:TS:2010:4292. 
vidad privada de la Administración. De todos modos, es sabido que la normalidad o anormalidad en el funcionamiento del servicio resulta irrelevante para que nazca el deber de responder por la lesión causada, pues es suficiente con que el quebranto producido se deba a una actividad administrativa dañosa, aunque en la realización de esa conducta no se pudiera apreciar culpa o ilegalidad alguna.

\subsection{La relación de causalidad entre la acción y el daño sufrido: el supuesto de los planes urbanísticos anulados por causas externas y sobrevenidas}

En la materia que nos ocupa, la relación causa-efecto entre la acción y el daño puede obedecer a circunstancias más o meno remotas, e incluso sobrevenidas en el tiempo ${ }^{34}$.

Un posible ejemplo de cuanto afirmamos y que mejor ilustra este planteamiento podría encontrarse en el pronunciamiento judicial que condujo a la anulación del PGOU de Santander, del año 2012.

Un año después de la aprobación de este instrumento de planteamiento, se anuló el proyecto de construcción de la principal infraestructura de abastecimiento de agua a la ciudad en época de estiaje: el llamado Bitrasvase, que constituye una obra pública hidráulica, declarada de «interés general» del Estado ${ }^{35}$, que ya se encontraba previamente en funcionamiento.

Según se indica en STS de 18 de diciembre de $2013^{36}$, la anulación del Bitrasvase obedece a la falta de una mínima motivación de la evaluación de impacto ambiental a la que se sometió el citado proyecto de obra y en cuya tramitación la Administración autonómica actuó como órgano ambiental:

La Sala de instancia ha analizado el Estudio medioambiental que obra en el anejo 4 de la Memoria, tanto en relación con la ZEPA como con el LIC de referencia, expresivo de que el proyecto no tendría repercusiones significativas sobre tales lugares; $y$, tras hacer referencia a la jurisprudencia comunitaria respecto del concepto de «evaluación adecuada» del Art. 6.3 de la Directiva 92/43, deja constancia de la declaración efectuada por la autoridad responsable de supervisar los lugares de la citada Red Natura 2000, calificando la misma de «manifies-

34 Véase R. Fontela Guío (2002), «Responsabilidad patrimonial de la administración autonómica. Nexo causal. Causa eficiente o adecuada», CEFLegal: Revista Práctica de Derecho. Comentarios y casos prácticos, 12

35 Sobre la relación entre el planeamiento urbanístico y las infraestructuras hidráulicas de interés general, véase A. Embid Irujo (1995), «Régimen jurídico de las obras hidráulicas: planteamientos generales», en A. Embid Irujo (coord.), Las obras hidráulicas, págs. 25-76; Régimen jurídico de las obras hidráulicas: su incorporación por la Ley 46/1999 a la Ley de Aguas; S. Martín-Retortillo Baquer (2000), «La reforma de la Ley de Aguas: (ley 46/1999, de 13 de diciembre)», en A. Embid Irujo (coord.), Las obras hidráulicas, págs. 35-86.

Véase ECLI: ES:TS:2013:6493. 
tamente insuficiente» ya que la misma "no incluye una mínima motivación que justifique la conclusión a la que llega». Memoria, y conclusiones que contrasta con el informe acompańado con la contestación a la demanda. No podemos alterar dichas conclusiones cuando ni siquiera se califican las mismas de arbitrarias o ilógicas, debiendo ratificarse la conclusión alcanzada de nulidad, decretada en la instancia, por cuanto la insuficiencia de motivación no puede calificarse de un simple defecto formal determinante de simple anulabilidad.

La vinculación entre la anulación de esa infraestructura y la del PGOU queda consagrada en la sentencia de ese mismo Tribunal de 8 de noviembre de $2016^{37}$, en la que viene a indicarse lo siguiente:

Cuestión distinta de la anterior es la que se formula en el sexto de los motivos de la recurrente, en el que se considera que se ha producido la infracción del Art. 25.4 del Texto Refundido de la Ley de Aguas, aprobado por Real Decreto Legislativo 1/2001 de 20 de julio, por el que se aprueba el (TRLA), al quedar acreditado que no existen recursos hídricos suficientes para la población sin la utilización del denominado Bitrasvase [...] Pues bien, la tesis de la Sala de instancia es que se trata de una cuestión sobrevenida, que no fue planteada en la demanda [...] Más, con independencia de ello, lo cierto es — aunque por una circunstancia «externa» al PGOU - que este debe de ser anulado, así como la Resolución aprobatoria del mismo. Anulados el proyecto y la obra del Bitrasvase por el Tribunal Supremo, la existencia de recursos hídricos para la ciudad de Santander queda en entredicho, y, su suficiencia, en modo alguno acreditada, con vulneración del Art. 25.4 del TRLA.

Por tanto, cabe afirmar que la declaración de ilegalidad del citado proyecto de obra se erige en causa idónea y relevante por sí misma para producir el resultado final; es decir, dicha circunstancia actúa como conditio sine qua non para la anulación del PGOU y podría añadirse que, al menos potencialmente, opera como motivo directo de la lesión o perjuicios que pudieran derivarse de esa circunstancia ${ }^{38}$.

Para poder establecer esa relación de causalidad, a efectos de una eventual declaración de responsabilidad patrimonial, resulta preciso, en todo caso, que, entre el deficiente funcionamiento del servicio y la lesión producida, no haya interferido en modo alguno la acción de la Administración autora del

37 Véase ECLI:ES:TS:2016:4838. La falta de justificación de la disponibilidad de recursos hídricos es, justamente, una de las circunstancias que con mayor asiduidad han determinado en los últimos años la anulación de planes urbanísticos por parte de los tribunales de justicia. Acerca de este extremo, véase J.A. Ramos Medrano (2017), «Más de 90 planes de urbanismo anulados judicialmente por no justificar la disponibilidad de recursos hídricos», Actualidad Jurídica Ambiental, 67, págs. 1-20.

38 Véase, en sentido contrario, FD séptimo, 1º, de la Sentencia 380/2020, de 1 de diciembre de 2020, del TSJ de Cantabria (rec. 296/2018). 
plan $^{39}$. Al respecto, señala el Tribunal Supremo, en sentencia de 23 de octubre de $2009^{40}$, que:

La obligación de responder de los daños y perjuicios sufridos, que se identifican con los gastos de demolición reclamados o realizados en sustitución de los terceros perjudicados en la cuota que en su caso se determine en los procesos en los que se reclame por los mismos, tiene su causa en la propia actuación de la Administración reclamante sin cuya participación no le sería exigible responsabilidad alguna, de la que no queda exonerada por la concurrencia a la producción del resultado de otra Administración pública, exoneración que solo tiene lugar cuando la Administración que invoca el perjuicio no participa en la producción del resultado lesivo que se atribuye, exclusivamente, a la Administración demandada, que no es el caso.

No siendo así, parece lógico que la Administración que promueve la redacción del planeamiento e impulsa su tramitación deberá entenderse amparada por la legítima confianza o fiabilidad que le ofrecen los informes preceptivos recabados de los organismos sectoriales competentes ${ }^{41}$, ya que, al mismo tiempo, se ve forzada a introducir las correcciones o cambios que le hayan sido exigidos en virtud de esos mismos informes y, en último término, está sujeta al ejercicio del control de legalidad que lleva a cabo la Administración competente.

Igualmente, al elaborar sus previsiones de crecimiento de población, y emprender la redacción de un plan urbanístico, la Administración responsable está legitimada para tomar en consideración todos los recursos e infraestructuras disponibles.

En este sentido, y tal y como hemos indicado en otras ocasiones, las obras públicas declaradas de interés general e incluidas en su listado de inversiones son de obligada ejecución desde el punto de vista jurídico ${ }^{42}$.

Sobre esta cuestión, la SAN de 1 de junio de 2005 resulta claramente ilustrativa al objeto de inferir — a contrario sensu - la existencia de una obligación

39 Véase V. E. Ruiz Díaz (2019), «Responsabilidad patrimonial: la ruptura del nexo causal. La intervención de la víctima en la producción del daño», Consultor de los ayuntamientos y de los juzgados: Revista técnica especializada en administración local y justicia municipal, 4, págs. 99-109.

40 Véase ECLI: ECLI:ES:TS:2009:6594.

41 Véase J. Galán Cáceres (2015), «Responsabilidad patrimonial de la Administración: Principio de confianza legítima en la actuación de la Administración: (Comentario a la STS de 31 de octubre de 2014)», CEFLegal: revista práctica de derecho. Comentarios y casos prácticos, 170, págs. 137-141; L. Medina Alcoz (2006), «Confianza legítima y responsabilidad patrimonial», Revista Española de Derecho Administrativo, 130, págs. 275-326.

42 Véase J.F. Fernández García (2011), «La declaración de interés general de las obras hidráulicas y su incidencia sobre la obligación de tratamiento de las aguas residuales vertidas a los ríos», Revista Aranzadi de Derecho Ambiental, 19, I, pág. 136. 
efectiva del Estado, en orden a proceder a la ejecución de este tipo de infraestructuras, una vez cumplidos los requisitos necesarios legalmente establecidos:

En el presente caso no se cumplen los requisitos razonados para que la pretensión de la parte actora se ajuste a lo prevenido en el referido Art. 29.1 de la LJCA, pues no se aprecia, cuando se efectúa el requerimiento de la actora, que exista por parte de la Administración demandada una concreta obligación que tuviera que cumplir con relación a aquel Ayuntamiento [...] hasta que no entra en vigor la Ley que aprueba el Plan Hidrológico Nacional, ese concreto proyecto de abastecimiento de agua al Ayuntamiento demandante no se declara de interés general del Estado. Esta declaración, además, no supone tampoco una obligación inmediata del Estado de ejecutar esa obra, pues se efectúa a los efectos de la Legislación sobre Expropiación Forzosa, lo que implica actos posteriores de aplicación (proyectos, procedimiento expropiatorio, etc.) y, aparte, en su Art. 36.3 establece un plazo temporal para el desarrollo de las inversiones relacionadas en el anexo II, entre las que se encuentra ese proyecto de abastecimiento, que se concreta en el período 2001-2008.

Cabe igualmente entender que ese nexo causal tampoco se vería necesariamente interrumpido por la eventual legalización posterior de este tipo de infraestructuras o la subsanación, en general, de los vicios que hayan conducido en última instancia a la anulación del planeamiento.

Ese hecho no tendría ninguna virtualidad para que un instrumento urbanístico pueda recobrar su eficacia, lo que hace que el daño producido deba ser indemnizado, pues el vicio no resulta convalidable ${ }^{43}$.

En este sentido se pronuncia de forma unánime la jurisprudencia, siendo muestra de ello la STS de 6 de septiembre de $2016^{44}$, en la que se señala lo siguiente:

Así es, no se puede subsanar, enmendar, o convalidar el plan nulo. Tampoco pueden conservarse los acuerdos de aprobación definitiva y otros que se mantienen como si las determinaciones del plan no hubieran sido declaradas nulas de pleno derecho. Así, pues, el ejercicio de dicha potestad requiere la tramitación de un procedimiento desde su inicio, como resaltamos precisamente en la indicada resolución. En definitiva, deja de resultar viable el mantenimiento de la misma ordenación urbanística y procede plantear una nueva ordenación. Pues bien, nuestro ordenamiento jurídico reserva para las disposiciones generales que hayan vulnerado

43 Véase C. Xiol Ríos (2015), «Conservación de los actos de aplicación tras la anulación de una figura de planeamiento: planeamiento. Actos de gestión", La administración práctica: enciclopedia de administración municipal, 7, págs. 133-138. Sobre la necesidad de un cambio de paradigma en este punto, véanse Fernández García (2016: 435); Fernández Rodríguez (2017: 137).

44 Véase ECLI:ES:TS:2016:4042. 
la Constitución, las leyes u otras disposiciones administrativas de superior rango, la consecuencia más severa: la nulidad plena, ex Art. 62.2 de la Ley 30/1992.

\section{LA POSIBILIDAD DE QUE TERCEROS PERJUDICADOS TAMBIÉN PUEDAN DIRIGIRSE FRENTE A LA ADMINISTRACÍÓN QUE HA SUFRIDO EL DAÑO}

Por último, debemos señalar que la posibilidad de que la Administración autora del plan pueda formular reclamación de responsabilidad patrimonial frente a otra no excluye que, si se dan las condiciones legalmente establecidas, deba responder previamente de las consecuencias que la anulación de ese instrumento pueda llegar a producir frente a terceros ${ }^{45}$.

Según lo advertido ya, es evidente que la anulación del PGOU puede llegar a arrastrar consigo la de aquellos convenios urbanísticos que pierden la cobertura jurídica que les dio amparo, provocando que la Administración pública que los ha suscrito deba compensar a la otra parte por las contraprestaciones ya efectuadas, dado el carácter sinalagmático de esta clase de instrumentos.

Recordemos que, dado que la anulación del PGOU tiene efectos ex tunc, el acuerdo que condujo a su aprobación es como si nunca hubiese tenido lugar. Consecuentemente, de no indemnizarse al interesado, se estaría produciendo un enriquecimiento injusto por parte de la Administración pública que impulsó la aprobación de aquel.

Nos remitimos en este punto a lo señalado en STS de 11 de mayo de $2016^{46}$ :

[...] los indicados convenios tienen efectos entre las partes y obligan a los que lo suscriben, si bien no imponen al planificador a seguir un modelo urbanístico determinado, que mantiene indemne su potestad discrecional, toda vez que el ejercicio de tal potestad no es disponible por vía contractual, y ha de estar, en todo caso, presidida por el interés general [...] [ello] habilita a las partes a resolver el convenio con devolución de las correspondientes prestaciones; en caso de imposibilidad, a indemnizar dańos y perjuicios conforme al art. 1124 del CC.

45 Véase J. D. Sanz Heredero (2016), «Consecuencias jurídicas de la declaración de nulidad de los instrumentos de planeamiento sobre las licencias urbanísticas y situación jurídica de los terceros adquirentes afectados", Práctica urbanistica: Revista mensual de urbanismo, 141; VV. AA. (2008), «Anulación por Sentencia de un Plan General: efectos sobre los actos y acuerdos dictados a su amparo", Consultor de los ayuntamientos y de los juzgados: Revista técnica especializada en administración local y justicia municipal, 14, págs. 24592460; A. Alonso Clemente (2012), "Responsabilidad patrimonial derivada de las potestades administrativas en materia de urbanismo», Práctica urbanistica: Revista mensual de urbanismo, 113, págs. 68-88.

46 Véase ECLI:ES:TS:2016:2167. 
En orden a la aplicación del referido art. 1.124 CC, debe indicarse que la doctrina judicial ha sufrido una cierta evolución, pues inicialmente partió de excluir la posibilidad de resolver un contrato o un convenio en los casos en los que el incumplimiento escapase a la voluntad o la acción de las partes firmantes ${ }^{47}$.

De ello resulta expresiva la STS de 28 de diciembre de $1987^{48}$, en la que se contiene la siguiente doctrina:

No es congruente afirmar que, a todos los efectos, es indiferente que el incumplimiento sea voluntario o no, y habida cuenta de que, si concurría un hecho obstativo impediente de la satisfacción total de la prestación, que se constituía por la modificación del planeamiento urbanístico, el mismo resultaba insuperable por los contratantes, por no ser «interno, intrínseco o ínsito» respecto del convenio, que es lo que la sentencia de 28 de junio de 1983 exige para que pueda apreciarse la causa de fuerza mayor, como el Tribunal «a quo» acertadamente estimaba, dado que ésta consiste, según las de 23 de octubre de 1969, 9 de junio de 1976 y 24 de diciembre de 1985 — recaídas, por cierto, en supuestos contemplados por el referido artículo-, en un «suceso que está fuera del círculo de actuación obligado que no hubiera podido preveerse o que, previsto, fuera inevitable», lo que supone la total extrañeidad del acontecimiento en relación con la parte obligada, como también requieren las de 12 de marzo de 1956, 19 de mayo de 1960 y 11 de diciembre de 1978, todo lo cual determina que la pretensión de apelación sea desestimada.

Bajo ese planteamiento, los tribunales han excluido la resolución de los contratos y convenios en los casos en que no se apreciase una voluntad deliberada de incumplir lo acordado e, igualmente, cuando han advertido la voluntad explícita de una de las partes de solucionar las causas que provocaron ese incumplimiento.

Así, la SAP de Valencia de 15 de enero de $2001^{49}$, con cita de doctrina del Tribunal Supremo, señala:

Para que haya lugar a la resolución no basta que el incumplimiento sea de tal naturaleza que disminuya la utilidad de la prestación con respecto a la contraprestación sino que es necesario igualmente que el perjuicio no sea fácilmente subsanable con un medio de técnica jurídica distinto del de la resolución. Que ello es así se

47 Véase J. A. Doral García de Pazos (2013), «El exceso de Derecho Civil (a propósito del art. 1124 del C.Civ.)», en J. J. Rams Albesa (coord.), Estudios de derecho civil, pgas. 445-470; J. J. Pintó Ruiz (2011), «Estudio sobre el art. 1124 del C.Civ.», Anales de la Real Academia de Jurisprudencia y Legislación, págs. 535-590; M. E. Clemente Meoro (2011), «Artículo 1124. Facultad de resolver las obligaciones», en R. Valpuesta Fernández y A. Cañizares Laso (dirs.), C.Civ. comentado, Vol. 3, (Libro IV. De las obligaciones y contratos. Teoría general de la obligacion y el contrato (Artículos 1088 a 1444), págs. 229-239.

48 Véase RJ 198719848.

49 Véase JUR 2001\98502. 
desprende, sin ningún genero de dudas, del párrafo tercero del mismo art. 1.124 del CC cuando dice que el Tribunal decretará la resolución que se reclame a no haber causas justificadas que le autoricen para señalar plazo, lo que implica una atribución legal a los Tribunales para acceder o no a la resolución según la gravedad del incumplimiento, moderando en consecuencia el rigor de una automática resolución cuando no se demuestre de modo indubitado una patente voluntad deliberadamente rebelde al cumplimiento de lo convenido.

Igualmente, la SAP de Palencia de 29 de diciembre de $2006^{50}$, concluye:

[...] Limitación en la pretensión deducida en la demanda que es consecuencia de la facultad de moderación de las pretensiones resolutorias o de cumplimiento en sus términos de los contratos que atribuye a los Tribunales el párrafo tercero del art. 1.124 del C. Civil, facultad admitida por la jurisprudencia a fin de moderar «el rigor de una automática resolución cuando no se demuestre de modo indubitado una patente voluntad deliberadamente rebelde al cumplimiento de lo convenido" (S. TS. 18 de noviembre de 1994) y consustancial al principio que debe regir en esta materia, el de conservación del negocio, máxime en un supuesto como el presente, en que las entidades demandadas han mostrado en todo momento voluntad de solucionar los problemas.

Hoy en día, sin embargo, como señala el Tribunal Supremo, en su sentencia de 31 de mayo de $2007^{51}$, ese planteamiento se ha visto superado y corregido:

Como se ha declarado en la reciente Sentencia de 20 de septiembre de 2006 (recurso núm. 3818/1999), «la jurisprudencia, ha abandonado hace tiempo las posiciones que, de una $u$ otra forma, exigían una reiterada y demostrada voluntad rebelde en el incumplimiento de las obligaciones contractuales, o, en otros casos, una voluntad obstativa al cumplimiento, para afirmar en la actualidad que basta atender al dato objetivo de la injustificada falta de cumplimiento, siempre que tenga la entidad suficiente para motivar la frustración del fin del contrato (Sentencias de 7 de mayo de 2003, 18 de octubre de 2004 y 3 de marzo de 2005, entre otras)» [...] Por ello el Tribunal declaró en tal caso que «la frustración no se produce cuando la causa que origina el incumplimiento no es atribuible directamente a las partes [...] y lo mismo sucede cuando inciden impedimentos urbanísticos y administrativos.

A esa nueva corriente jurisprudencial se adscribe la STSJ de Madrid de 5 de julio de $2016^{52}$, en la que se mantiene la obligación de indemnizar en los supuestos de incumplimiento, a pesar de que este no obedezca a un hecho imputable al deudor:

50 Véase JUR 2007\255439.

51 Véase RJ 2007\4336.

52 Véase ECLI:ES:TSJM:2016:8583. 
La acción ejercitada por la demandante, de rescisión contractual por incumplimiento, se ha de encuadrar en el artículo 1.124 del C. Civil, habida cuenta, como arriba se anticipó, de la naturaleza contractual de los convenios urbanísticos. Este precepto legal prevé que un contrato, tal es un convenio urbanístico como el presente, produce obligaciones recíprocas [...]. Ha de tenerse en cuenta siempre el artículo $1.101 \mathrm{C}$. Civil: "Quedan sujetos a la indemnización de los dańos y perjuicios causados los que en el cumplimiento de sus obligaciones incurrieren en dolo, negligencia o morosidad, y los que de cualquier modo contravinieren al tenor de aquélla». La interpretación jurisprudencial de dichas normas, según sentencia de esta Sección de 8 de abril de 2016, recurso no $1643 / 2015$, se resume en las siguientes conclusiones: $1^{\circ}$ ) Que las obligaciones sean recíprocas y que la obligación incumplida sea principal; $2^{\circ}$ ) Que el que ejercita la acción haya cumplido su parte de obligaciones salvo que ello ocurriera como consecuencia de un incumplimiento anterior del otro en cuyo caso resulta liberado del compromiso; $3^{\circ}$ ) Que se decrete judicialmente la resolución pues no basta la mera declaración de haberse resuelto el contrato por parte de quien lo pretende cuando hay desacuerdo entre los contratantes y $4^{\circ}$ ) Que el incumplimiento del demandado en cualquier forma de sus obligaciones se haya producido por un hecho imputable o no al deudor.

Por tanto, aunque no quepa achacar a la Administración que firma el convenio la causa del incumplimiento, difícilmente ese hecho puede enervar los efectos del art. 1.124 del CC.

No cabría, pues, sostener que esa Administración pueda libremente optar por tramitar un nuevo planeamiento o que no esté obligada a indemnizar a los interesados, pues — como ya se dejó expuesto- el ejercicio de la acción del referido art. 1.124, por incumplimiento contractual, deja en manos de estos la posibilidad de optar por la resolución del convenio, vinculando con su decisión a la Administración pública impulsora de la aprobación del PGOU anulado.

\section{CONCLUSIONES}

A tenor del análisis realizado en los epígrafes anteriores, cabe formular las siguientes conclusiones en relación con la cuestión objeto de examen:

1. Cuando una Administración resulta condenada al pago de la correspondiente indemnización a un particular, con motivo de los daños derivados de la anulación de un plan urbanístico, podrá ejercitar la correspondiente acción de regreso o de repetición frente aquellas otras Administraciones u Organismos públicos que han concurrido, junto a ella, a la producción del hecho dañoso. Respecto de la víctima, esa deuda tiene carácter solidario, mientras que, en la relación interna entre los Entes públicos causantes del daño, opera la presunción de imputación por partes iguales, que se deriva del art. 1.138 del Código Civil. 
2. La anulación de cualquier figura del planeamiento también puede producirse por circunstancias totalmente ajenas a la acción de la Administración pública que impulsó su aprobación, colocándose esta en una posición similar a la de un particular que ve frustrada una actuación urbanística en marcha, como consecuencia de la anulación sobrevenida del instrumento jurídico que le servía de cobertura. El resarcimiento del daño que ese hecho provoca parece oportuno que pueda dirimirse a través de la acción de responsabilidad patrimonial entre Administraciones públicas, por más que ambas actúen en el ejercicio de potestades propias de igual rango.

3. En este sentido, y pese a la doctrina extendida del Consejo de Estado, del que se han hecho eco algunos pronunciamientos judiciales, procede proclamar que no existe un principio general de inmunidad en las relaciones interadministrativas, por lo que no cabe aplicar una interpretación restrictiva en este punto, máxime en aquellos supuestos en los que las Administraciones públicas actuantes operan en ámbitos funcionales perfectamente diferenciados.

4. En la esfera urbanística, la teoría de la actio nata puede sufrir ciertas modulaciones, particularmente cuando la anulación del plan arrastra consigo a los convenios urbanísticos suscritos por la Administración impulsora del citado instrumento, ya que una eventual reclamación de responsabilidad patrimonial por este motivo solo es posible una vez que se ha sustanciado el procedimiento conducente a la resolución de dichos convenios, al amparo del art. 1.124 del CC.

5. Aunque solo ciertos vicios causantes de la anulación de un acto o disposición administrativa convierten el daño en antijurídico y, por tanto, en indemnizable, debe entenderse que concurre dicho requisito cuando la lesión patrimonial sufrida obedece a decisiones que han sido anuladas por la carencia de una mínima motivación, pues en esos supuestos no es posible entender que la actuación desplegada por la Administración pública se haya enderezado a satisfacer los fines para los cuales se le otorgó la potestad que ha venido a ejercitar, sino que dicha actuación habrá de reputarse como irracional o arbitraria.

6. Los posibles títulos de imputación de la responsabilidad patrimonial de una Administración frente a otra en el ámbito urbanístico pueden derivar de un deficiente control de la legalidad por parte del órgano encargado de la aprobación definitiva del planeamiento. No obstante, en ocasiones, ese título de imputación puede verse desplazado por la intervención de otras Administraciones u Organismos públicos. Así ocurre, en particular, con la emisión de aquellos informes sectoriales que operan con carácter vinculante en el procedimiento de tramitación del plan; entre ellos, los que avalan la falta de afección de estos instrumentos a determinados espacios naturales o los que acreditan la suficiencia de recursos hídricos para el abastecimiento a la población, en aquellos ámbitos en los que el plan prevé nuevos desarrollos urbanísticos. 
7. El nexo entre la acción y el daño patrimonial sufrido puede mantenerse vivo cuando la anulación de un plan obedece a causas externas y sobrevenidas a este. Si esas causas resultan ser achacables a la intervención de otras Administraciones públicas, aunque no sea en el procedimiento que condujo directamente a la aprobación del plan, pueden ser determinantes para que nazca el deber de resarcimiento. Si tal circunstancia actúa como conditio sine qua non a efectos de la anulación de ese instrumento en base a lo declarado en sentencia judicial firme, deberá entenderse que opera, igualmente, como causa idónea y relevante de la responsabilidad patrimonial que surge entre las Administraciones públicas actuantes. 
